\title{
Understanding digital-altered photographs through photographers' views of reality: Matt Siber as an example
}

\author{
Yi-hui Huang \\ East Stroudsburg University \\ 200 Prospect Street. East Stroudsburg, PA 18301, USA \\ yhuang@po-box.esu.edu
}

\begin{abstract}
Digital-altered photographs are now popular among artists due to advancements in digital technology. Manipulating or gathering pieces of images and combining them into one in computers, artists who produce digital-altered photographs not only deliver impressive technological effects for shock value, but also, and perhaps more importantly, capitalize on the style's ability to express their particular messages. To understand digital-altered photographs and the messages behind them, I propose that we start with investigating artists' worldviews, or what artists value as knowledge. This inquiry can be achieved by asking about artists' views of reality and by examining how their views of reality manifest in their digital-altered photographs. Contemporary photographer Matt Siber and his digital projects, Floating Logos and The Untitled Project, provide an example of how investigating digital photographers' views of reality and interpreting these views through theories can help us identify and clarify the valuable knowledge provided by their work.
\end{abstract}

Digital photography. Photography aesthetics. Reality.

\section{INTRODUCTION}

With the rapid advancement of technology in the photographic industry, more photographers than ever, willingly or half-heartedly, are replacing their darkroom-based facilities with digital ones (Sung, 2008). This technological shift has changed the focus of artists' art making process, in that now photographers spend more time editing their photographs with Photoshop than finding a "perfect" scene. The ability to conveniently modify photographs after shooting them has created a new style of photography - digital-altered, which can be combinations of different pieces of images in one (Skopik, 2003), or any modification to the original photograph. Photographs of this style are carefully knitted together or transformed using a computer, which is replacing the "old-fashioned" technique of pressing a single shutter button. At the same time, photographers who digitally combine pieces of images are anxious to draw attention away from the sophisticated Photoshop technical skills required to make these images (Huang, 2008). These photographers have more important messages to communicate through their art than the impressive effects and shock value conveniently created by the digital tool. After all, artists' choices of media and styles are not carefree, but are laden with scrupulous thinking, including the ideas and beliefs through which they interpret and interact with the world. In other words, artists/photographers who use digital tools have certain messages that they can convey only through the digital-altered style.

In order to understand an artist's important message beneath his or her digital fantasies, I propose that we investigate the artist's worldview, or what $s /$ he values as knowledge. As contemporary architectural theorist Mark Gelernter (1995) suggests, knowledge is the foundation of one's intention, ideas, and thus, forms of artwork. If we understand how a photographer sees the world, we can have a better idea about the principles guiding his or her art making. A more approachable way to inquire into a digital photographers' knowledge is to ask about his or her views of reality (Alston, 2006), with questions such as "What is your definition of reality?" "What notion of reality do you represent in your photographs?" and "How do you visualize your reality in photographs?"

In the following section, contemporary photographer Matt Siber's photographic projects Floating Logos and The Untitled Project are cited as an example of how we can understand a body of 
digital-altered work, beginning with an investigation of the artist's worldview. The information about Siber and his work is mostly based on an interview I conducted with the artist on December 20, 2006 in his Chicago studio. I also referred to Siber's artist statement and critics' evaluation of his work.

Herein, I first introduce Siber's photography creation process, including his initial feelings, thoughts, ideas, and the actual production. I then relate Siber's definition of reality, and strategies he employs to visualize reality in his photographs. Next, I interpret Siber's views of reality and cite suitable theories, such as postmodernism, to explicate his work. I attempt to concretize Siber's view of reality by discussing his idea of the work and his fabrication of the images. Finally, I conclude with the types of knowledge provided by Siber's photographs, from which we gain a better understanding of his art.

\section{MATT SIBER'S FLOATING LOGOS AND THE UNTITLED PROJECT}

Matt Siber, a Chicago-based artist, invokes an awareness of influences, forces, power, and control executed among people by advertising, corporate branding, and government propaganda through the omnipresent signage in public spaces. In Floating Logos, Siber photographs tall corporate logos frequently seen in the Midwest, and in The Untitled Project, he depicts advertisements or street signs in urban scenes. Siber then applies various digital techniques to alter the images, in an effort to defy the power of capitalism.

In Floating Logos, Siber humorously exaggerates the nature of signage by exalting it to a godly state. By digitally eliminating the tall poles or stanchions supporting those signs from the images, corporate logos such as McDonald's, Shell, or Jack-in-thebox are shown literally floating above the earth and thus gaining a supernatural quality. Those signs, seeming to forever maintain perfection and hover over us, "profoundly affect our lives, yet [are] just beyond our control" (Siber, artist statement).

In The Untitled Project, Siber digitally separates the text from the images of urban settings that he photographs, and reintroduces those same texts in an adjacent graphical layout. Siber explains that his initial approach to The Untitled Project was different from the present one. Originally, he only removed the text from public spaces without re-presenting it in another layout, in hopes of "free[ing] the modern citizen from the onslaught of language that is ubiquitous in our environment" (Siber, 2005). However, Siber realized that simply silencing the literal part of communication does little to diminish the power delivered from the signage. Originating from Siber's interest in how power manifests among people, the separation of the text highlights the hegemony of multiple forms of mass communication including not only text, but also colours, logos, symbols, graphic design, and photographs. By co-presenting the literal and the visual in separated panels, Siber "turn[s] the project into a study through deconstruction rather than an attempted liberation" (Siber, 2005).

For example, in Untitled \#13, the gold colour of the Christian Dior advertisement signifies luxury, wealth, and high rank. With repeated exposure to golden Dior advertisements, viewers are trained to recognize the brand identity even when the brand title itself is stripped from the image. Similarly, we can recognize a certain style of TV commercial when the brand name Target, or even the red target icon, is not shown. Also, we have been so educated by traffic signs that we do not need the word 'stop' in stop signs to tell us to stop, but we grasp its meaning simply by its being red and octagonal.

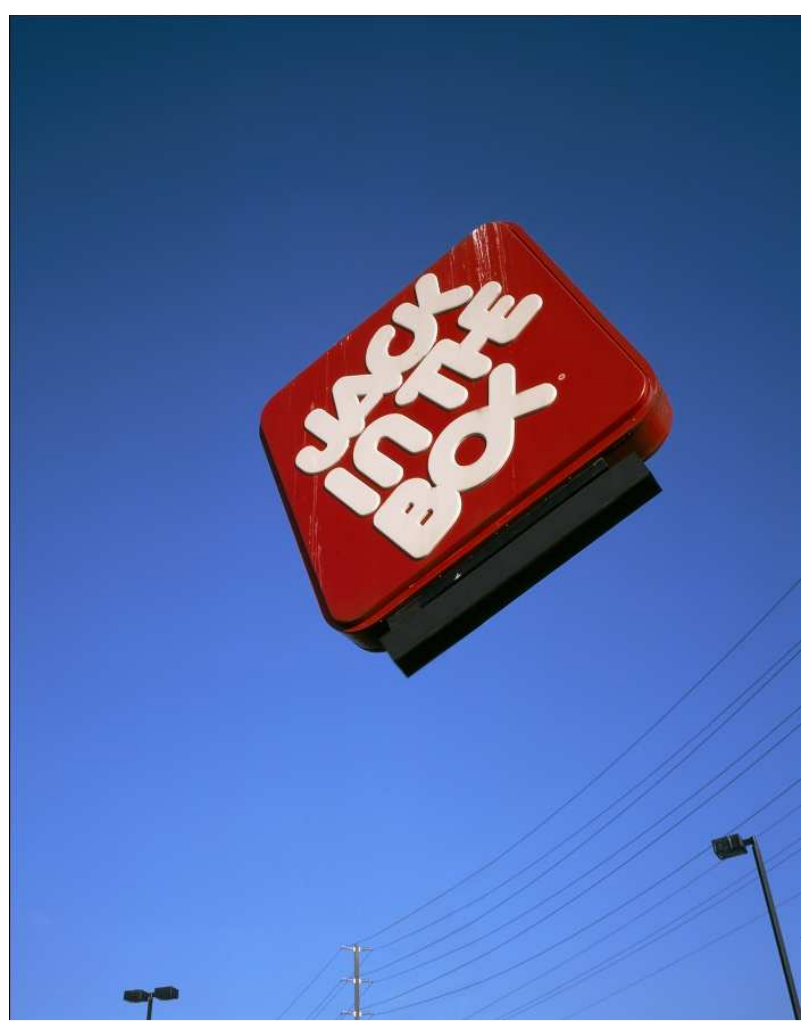

Figure 1: Matt Siber. Floating Logos-Jack in the Box, 2003. 40X32 inches. Inkjet print. Courtesy of the artist.

Siber explains his aesthetic criteria in image production. First of all, the photograph has to be well-composed, which indicates a close relationship among signage, people, and landscape. Also, sophisticated digital synthesis skills are required to seamlessly combine several shots into one image to improve the composition. As for the text piece, 


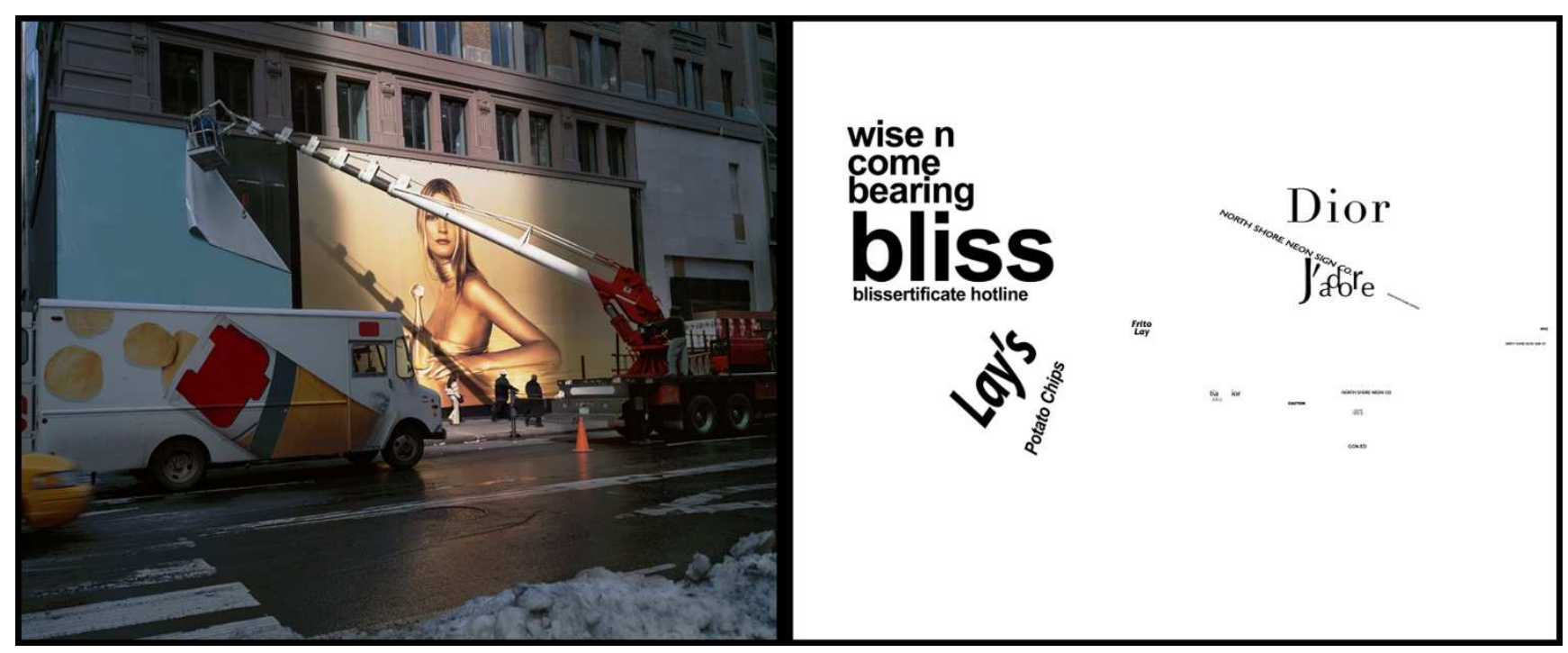

Figure 2: Matt Siber. The Untitled \#13, 2003. 40x32inches. Inkjet print. Courtesy of the artist.

when photographing urban scenes, Siber would pay a lot of attention to what the signs said and pre-visualized how the text would look on a white piece of paper. However, this process became problematic when extending the project to Europe and Japan, where the text and signs became less comprehensible to him. As for how to present them, all of the text in the piece is black, true to the original font typeface, position, and graphic design, whether it is arched, circular, or vertical.

When asked about views of reality, Siber suggests putting all 'reality' in quotation marks, and will not give a definition of the word. He considers 'reality' an absurd idea. The present and himself are real to him, but their contingency is difficult to control - it is even impossible to look at the fleeting present twice, and Siber's perception changes drastically with what he reads and learns on a daily basis. As for physical 'realities' - such as something he can touch or feel - he believes they are there, but they are not of interest to him, and thus there is no need for discussion. Siber admits that objective 'realities' such as time and space exist, but since we cannot climb out of our heads to perceive things, everything objective becomes subjective, and hence objective 'reality' becomes irrelevant. In Siber's view, all 'realities' are subject to an individual's background and relate to an individual's perception, and hence are all filtered and subjective.

However, Siber embraces hyperreality wholeheartedly. Echoing Baudrillard, he states: "TV is enormous reality; it is such a reality in terms of the significance to the culture, and how it influences the culture and the people in the world" (personal communication, December, 20, 2006). Not only TV, but also fashion advertising photography has repeatedly produced so idealized and heightened a 'reality' as to tell people what they should strive for, to the degree that such 'reality' of perfection has been ingrained in people's psyches.

When asked if his digital-altered photographs represent his own 'reality,' Siber prefers the term 'reference' to the term 'represent.' According to Siber, since hyperreality has become part of people's mentality, it falls under the category of subjective 'reality,' or personal perception. Siber's Floating Logos and The Untitled Project reflect his own personal experience and idea about how we fall pray to the control of signs.

Truth in photography is another traditional view against which Siber argues. Photographing scenes in the world, Siber calls his work "a document of sorts, but not in the traditional sense" (personal communication, December, 20, 2006). In his view, his new document abandons the modernist notion of 'truth' inherited from traditional straight photographs, and makes use of the digital tool with non-straight techniques to present his subjective perception of the human condition. For Siber, the purpose of the new documentary photographer as social commentator is to raise people's awareness of the world around them and to polish their scepticism. Siber's view on the difference between modernist and postmodernist documentary can be seen in the assignment, 'The New Photographic Document,' that he gave to his students in his Introduction to Digital Photography class:

\section{Due Nov. 1: The New Photographic Document}


Traditional documentary photography places enormous importance on the "truth" of the unmanipulated photograph. Photograph what you see with no influence from the photographer and no creative interpretation in the darkroom. Over the past thirty years, Post-modern cynicism has caused us to question the veracity of the "truth" ideal in photography.

With the recent emergence of digital photography as the current industry standard, some photographers and artists have attempted to redefine the notion of the photographic document by presenting us with manipulated, or highly subjective imagery that still bears witness to the human condition.

For this assignment, I want you to make images that go beyond the traditional modernist notion of the photographic document. This could involve digital manipulation, unusual presentation or some other techniques that varies from the straight darkroom print. Conceptually, that images should allow the viewer to see the world around them in a different way, as a result of your non-traditional treatment of the images, but there should still be a clear enough connection to reality to consider it as a form of document. Six prints due (Siber, class syllabus, 2007).

Despite the manipulation or any other nontraditional techniques to set the new document apart from the modernist type of document, Siber insists that the appearance should remain documentary-like, in order to let the photograph look 'right.' Since we have been taught that a photograph should bear an indexical link to the physical world and thus should look believable, in Siber's view, photography's ability to record detail and its close relationship to the world have become its beauty and strength. In other words, Siber rejects the notion of truth in photography, while embracing the seemingly truthful look of photographs.

\section{THEORETICAL UNDERSTANDING OF SIBER'S WORK}

Siber states his view on reality quite firmly. Sensory, the most superficial layer of reality, is real to him, though not interesting as a topic of discussion. For Siber, 'reality' is personal perception, which is not only subject to each person's background and knowledge, but also contingent upon the new information and insights one gains every day. Due to the unpredictable distance between personal perception and socalled 'truth,' as well as the mutability of self, 'reality' is only referable, but not representable.
In particular, Siber points out that the influence of popular culture, where TV commercials and photographic advertisements are the main force, is so strong that the idea of perfection has become part of our ideology. This sense of perfection not only shapes our desire and occupies part of our personal perception, but also has become a portion of our subjective reality. Therefore, Siber's knowledge comes from his subjective interpretation of signs and active re-making of them, and can be explained as postmodernist. Siber's lexicon, such as deconstruct, power, and hyperreality, indicates his familiarity with postmodernism. Indeed, his perspective is very much influenced by Derrida, Foucault, and Baudrillard's theories, which can be used to account for his photographic projects.

Siber describes The Untitled Project as "a study through deconstruction" (Siber, 2005), which fits well in Derrida's theory of deconstruction. According to Derrida, deconstruction involves three phases: (1) to identify the conceptual binaries and overturn the implicit hierarchy; (2) to demonstrate the places of 'undecidables,' which do not fit comfortably into either of the two poles of a binary opposition; (3) to account for deferral and differential meaning, that is, differance (Derrida, 1971, 1972, 1981; Johnson, 1981; Silverman, 1983, Caputo, 1997; Deutscher, 2005). In The Untitled Project, Siber deconstructs the way of communication in public spaces. Initially, by simply eliminating text from public spaces, Siber attempted to put an end to the high volume of corporate signage. The presumed binary is the distinction between the literal and the visual form of communication. Text was traditionally favoured as a better form to deliver messages. However, removing the text does not completely eradicate the information. Siber found that from colours, the graphic design, photographs, logos, symbols, and architecture, one still receives the complete message. Therefore, by juxtaposing the visual and the literal in adjacent panels, he successfully proved that any alternative form of communication does as well as, or even better than, the textual form, and hence reverses the hierarchy of the binary of the text over the visual.

The second phase of deconstruction requires the identification of the undecidables. When Siber photographed some European countries where the language was not as familiar to him as English, the written text in signs lost its signified meaning and functioned just like graphics or pictures. Here, foreign text cannot be easily categorized into any poles of the binary between the visual and the literal, and hence puts the legitimacy of the binary into question.

Lastly, the third phase of deconstruction is to seek differance, the under-presented meaning repressed 
by the illusion of the self-enclosed identity. Various signs, whether they are commercial, municipal, propaganda, or news, not only give us the surface information about products, or directions toward certain places, but also enforce power through seducing advertisements or licensing documents to control our thought and behaviour. Siber recognizes the power of control as the differance of signs. As Baudrillard mentioned in America, "'Right lane must exit.' This 'must exit' has always struck me as a sign of destiny" (1989, p. 47).

By identifying the power flow, Siber's effort can also be considered as a Foucaultian project. Foucault's genealogy of power shows that power is not a single-direction force, but a field which consists of forces of repression, as well as resistance. By representing commercial signs which occupy a large portion of Siber's photographs, and by overstating and glorifying the nature of signs in Floating Logos, Siber not only shows the great intensity of power coming from the message givers and regulators, but also produces a counter-force from the oppressed side of the message receiver, the controlled. Completing the power field, Siber "counteract[s] the hegemony of a money-driven, consumer culture" (personal communication, December, 20, 2006). The Untitled Project untitles the space, and returns the hegemony back to the public. Although Siber considers his work more of a deconstructing study than an attempted liberation, it fulfils the aim of Foucault's tracing the genealogy of power to "disrupt the operation of normalizing practices" (Rawlinson, 1998, p. 226), and hence embodies liberating values (Wicks, 1998).

That signs reshape the self is the main concept of Baudrillard's hyperreality. In Baudrillard's view, what makes hyperreality firmly fixed in people's minds is the growing supremacy of objects (commodities, capital, fashion, media, and information) over subjects (people), and the eventual triumph of the object. Due to objects' obscene ecstasy in proliferation, expansion, and surpassing themselves, subjects' fascination with the play of objects turns to apathy and stupefaction. Therefore, as stated by Baudrillard, the sovereign power of the seductive object, or the commodities on television and advertisements that fascinate with their sign value, is affirmed. Siber certainly agrees with Baudrillard that in consumer society perpetuated by the media, people are caught up in the play of images and spectacles to the extent that the traditional concept of reality or truth does not matter any more; the sign is the only channel, and hyperreality is the only "reality" we can attain.

Siber's production of work is a postmodernist endeavour. First of all, his text-removing strategy deconstructs the conventional way of communication, and the act of appropriating images from popular culture troubles the line between high art and popular culture, both of which characterize postmodernist activities of photography (Crimp, 1980; Trodd, 1999).

Secondly, Siber's new document tries to arouse social awareness. This aim fulfills photographer and critic Allen Sekula's proposal and expectation of New Social Documentary, which challenges the modernist notion of the transcendental status of documentary photographs as fine art, discarding any contextual meaning. Similar to the New Social Documentary, Siber's photographic document critically refers to social truth by using a strategy beyond the conventionally convincing documentary style that merely presents the surface of the social realm (Sekula, 1978).

Postmodernist work as it is, however, Siber's aesthetic criterion discloses his modernist insistence. In the New Photographic Document assignment he gave his students, Siber gives complete freedom to manipulate the photographs; but the bottom line is that "there should still be a clear enough connection to reality to consider it as a form of document" (Siber, 2007). In his own work, Siber pursues seamlessness, where perspective, sharpness of grains, lighting, and scale are painstakingly maintained and harmonized. By keeping his photographs documentary-like, Siber emphasizes photographs' "indexical link to the physical world" (Siber, quoted in McDermott, 2007), which is a concrete way that we have been taught how to look at photographs. This act of going back and being true to the medium is what American critic Clement Greenberg (1905-1994) calls "selfcriticism" in art, where the uniqueness, and thereby the limitation, of the medium is realized. The uniqueness of the medium of photography, as theorized by the realist paradigm (Peterson, 1984), is the "automation characteristic of the photographic process" (p. 21), where photographic images are formed by means of a machine operation, and hence present a faithful record of the external world without man's intervention (Arnheim, 1974; Barthes, 1982; Bazin, 1982; Berger, 1980; Scruton, 1983; Sontag, 1977; Waton, 1984).

Apparently, Siber's insistence on the documentary look is not only a stylistic choice, but a moral imperative. Siber follows Sekula's (1978) postmodernist idea to offer social criticism, but chooses not to accept Sekula's proposed style of "theatrical and overtly contrived" (Sekula, 1978) artwork like John Heartfield's photo montages. Such intention to keep the non-traditional photographs photographic is a formalist trait, which adds a modernist aspect to Siber's thought and may contradict his postmodernist position. 
The abstract idea Siber tries to express in his photographs is the power among groups of people, and his strategy to convey it correspond to his validation of hyperreality. Finding a linkage between the manifestation of power and the function of signs exercised in public spaces, Siber focuses on the language of communication. By separating text from signs, or eliminating supporting poles to let logos drift in the air, Siber plays little tricks to call our attention and further pondering to the influence of signs. With glamorous color and immovable existence, Floating Logos exemplify Siber's view that corporate signs have shaped our thoughts, desires, and behaviour, and have become a form of hyperreality. By highlighting signage, Siber offers his 'reality,' or his personal reflection, on the power flow between corporations and people.

\section{CONCLUSION}

Probing into Siber's views of reality leads to a better understanding of the guiding principles that govern Siber's production of his projects and how he looks at the world. Siber's personal perception, contingent upon his background and everyday new knowledge, decides his contextualized pieces of knowledge. His Floating Logos and The Untitled Project illustrate the ideas of postmodernism, such as Derrida's deconstruction, Foucault's analysis of power, and Baudrillard's hyperreality. The knowledge that Siber's photographs provide is a postmodernist critique on the ways of communication, where power is heavily conveyed, yet seldom noticed. Siber's use of the digital tool entails postmodernist commentary on power-driven consumer society by manipulating the surface appearance of landscape in photographs, as well as modernist adherence to the solitary characteristic of the medium of photography by keeping the altered photographs seamless. In short, through Floating Logos and The Untitled Project, Siber communicates postmodernist and formalist ideas to his viewers.

Digital photographers have more important messages for viewers than simply demonstrating the technical skills required to make art using digital tools. Investigating digital photographers' views of reality and interpreting these views through theories help identify and clarify the valuable knowledge provided by their work, which therefore helps us better understand the meaning underneath the technological illusions.

\section{REFERENCES}

Alston, W. P. (2006) Epistemology and metaphysics. In T. M. Crisp, M. Davidson, \& D. V. Laan (eds), Knowledge and reality: essays in honor of Alvin Plantinga. Springer, Dordrecht, The Netherlands.

Arnheim, R. (1974) On the nature of photography. Critical inquiry, vol. 1, no. 1, 149-161.

Barthes, R. (1980) Camera Lucida. Hill and Wang, New York.

Barthes, R. (1982) A Barthes Reader. S. Sontag (eds). Hill and Wang, New York.

Baudrillard, J (1980) America. (C. Turner Trans.). Verso, London \& New York.

Baudrillard, J. (1983) Simulations. (P. Foss, P. Patton, \& P. Beitchman Trans.). Semiotext(e), New York.

Baudrillard, J. (1983) The ecstasy of communication. In $\mathrm{H}$. Foster (eds), The antiaesthetic: essays on postmodern culture. Bay Press, Port Townsend, Washington.

Baudrillard, J. (1983) Simulation. Columbia University, New York.

Baudrillard, J. (1990) The contemporary art market is beyond good and evil. Art International, 12, 5254.

Baudrillard, J. (1990) Fatal strategies. Semiotext(e), New York.

Baudrillard, J. (1993) The evil demon of images and the precession of simulacra. In T. Docherty (eds), Postmodernism: a reader. Columbia University Press, New York.

Baudrillard, J. (1994) Simulacra and simulation. The University of Michigan Press, Ann Arber.

Baudrillard, J. (1994) The illusion of the end. Polity Press, Oxford.

Bazin, A. (1960) The ontology of the photographic image. Film Quarterly, vol. 12, no. 4, 4-9.

Berger, J. (1980) Understanding a photograph. In A. Trachtenberg (eds), Classic essays on photography. Leetes's Island Books, New Haven.

Caputo, J. (1997) Deconstruction in a nutshell: a conversation with Jacques Derrida. Fordham University Press, New York.

Crimp, D. (1980) The photographic activity of postmodernism. October, Vol. 15, 91-101.

Derrida, J. (1971) Structure, sign, and play in the discourse of the human science. In R. Macksey \& E. Donato (eds), The Structuralist Controversy. The Johns Hopkins Press, Baltimore and London.

Derrida, J. (1972) Positions. (A. Bass, Trans). The University of Chicago Press, Chicago.

Derrida, J. (1981) Dissemination. (B. Johnson Trans.). The University of Chicago Press, Chicago.

Deutscher, P. (2005) How to read Derrida. W. W. Norton \& Company, New York.

Gelernter, M. (1995) Sources of architectural form: a critical history of Western design theory. 
Manchster University Press, Manchester and New York.

Johnson, B. (1981) Translator's introduction. In J. Derrida, Dissemination (B. Johnson, Trans.). The University of Chicago Press, Chicago.

McDermott, M. (2007) Interview with Matt Siber: proliferation of the image. Chicago City Arts Review.

http://www.chicagocityarts.org/content/view/1282/1 15/ (December 20, 2007).

Peterson, N. (1984) Photographic art: media and discourse. UMI Research Press, Ann Arbor, Michigan.

Pojman, L. (1991) Introduction to Philosophy: Classical and Contemporary Readings. Wadsworth, Belmont, CA.

Rawlinson, M. (1998) Michele Foucault. In M. Kelly (eds), Encyclopedia of aesthetics. Oxford University, New York.

Scruton, R. (1983) Photography and representation. The aesthetic understanding: essays in the philosophy of art and culture. Carcanet, Manchester.

Sekula, A. (1978) Dismantling modernism, reinventing documentary (notes on the politics of representation). In J. Liebling (eds), Photography: current perspectives. Light Impressions Co., Rochester, New York.

Siber, M. (2005) Visual literacy in the public space. Visual communication, v. 4, n. 1, 5-20.
Sekula, A. (1982) On the invention of photographic meaning. In V. Burgin (eds), Thinking photography. MacMillan Press Ltd, London.

Siber, M. (2006) Artist statement for The Untitled Project. http://www.siberart.com (December 30, 2006).

Siber, M. (2006). Artist statement for Floating Logos. http://www.siberart.com (December 30, 2006).

Siber, M. (2007). Course Syllabus for Introduction to Digital Photography. http://www.siberart.com (December 20, 2007).

Silverman, H. J. (1983) Writing (on deconstruction) at the edge of metaphysics. Research in Phenomenology, 13, 97-111.

Skopik, S. (2003) Digital photography: truth, meaning, aesthetics. History of Photography, 27, 264-271.

Sontag, S. (1977) On photography. Holtzbrinck Publishers, New York.

Sung, A. (2008) How has your view of fine-art photography changed in the digital realm. PdnEdu 7: 1, 62-64.

Trodd, C. (1999) Postmodernism. In S. Sim (eds), The Routledge critical dictionary of postmodern thought. Routledge, New York.

Walton, K. L. (1984) Transparent pictures: on the nature of photographic realism. Critical Inquiry, vol. 11 , no. 2, 246-277. 